\title{
OS IMPACTOS DO TELETRABALHO NA SAÚDE DO TRABALHADOR E O DIREITO À DESCONEXÃO LABORAL
}

\author{
Vanessa Rocha Ferreira * \\ Raissa Maria Fernandez Nascimento Aguilera **
}

\begin{abstract}
RESUMO: O presente artigo tem como finalidade discutir os impactos que o teletrabalho ocasiona na saúde física e mental dos trabalhadores, evidenciando a importância do direito à desconexão. A partir de um estudo teórico-normativo, analisa-se o regramento legal do regime de teletrabalho no ordenamento jurídico brasileiro. Posteriormente, discute-se as consequências que o excesso de trabalho, a não limitação da jornada, o isolamento social e o desrespeito ao direito ao lazer causam na saúde dos teletrabalhadores. Por fim, defende-se a necessidade de garantir o direito à desconexão como condição à concretização de direitos fundamentais dos trabalhadores, em especial o direito à saúde.
\end{abstract}

PALAVRAS-CHAVES: Teletrabalho; Tecnologia de Informação e Comunicação; Saúde do Trabalhador; Sobrejornada; Direito à desconexão.

\section{THE IMPACTS OF TELEWORK ON THE WORKERS' HEALTH AND THE RIGHT TO DISCONNECT}

\begin{abstract}
This article discusses the impacts that teleworking has on workers' physical and mental health, highlighting the importance of the right to disconnect from work. Based on a theoretical-normative study, the legal regulation of the teleworking regime in the Brazilian legal system is analyzed. Subsequently, it discusses the consequences that overwork, nonlimitation of work hours, social isolation and disrespect for the right to leisure cause on the health of teleworkers. Finally, the need to guarantee the right to disconnect is defended as an indispensable condition for the realization of workers' fundamental rights, especially the right to health.
\end{abstract}

KEYWORDS: Teleworking; Information and Communication Technology; Worker's health; Overday; Right to disconnect

\section{INTRODUÇÃO}

\footnotetext{
* Doutora em Direitos Humanos pela Universidade de Salamanca (USAL/ES). Mestre em Direitos Fundamentais pela Universidade da Amazônia (UNAMA/PA). Professora da Graduação e Pós-Graduação strictu senso do Centro Universitário do Estado do Pará (CESUPA). Auditora do TCE-PA. E-mail: vanessarochaf@ gmail.com. ORCID: https://orcid.org/0000-0001-5997-3198

** Mestranda em Direito, Políticas Públicas e Direitos Humanos pelo Centro Universitário do Estado do Pará (CESUPA). Especialista em Direito Material e Processual do Trabalho (CESUPA). Advogada. E-mail: raissafaguilera@gmail.com. ORCID: https://orcid.org/0000-0001-9641-4299
} 
Com o declínio do fordismo e a reestruturação dos modos de produção, conjuntamente com o acelerado desenvolvimento das tecnologias de informação e comunicação (TICs), o mundo laboral é redesenhado. Novos regimes e novos ambientes laborais se fazem necessários para contemplar as novas ambições de tempo e espaço exigidas pelo mercado. Assim surge o teletrabalho, nova modalidade de trabalhado, caracterizada pelo intenso uso de TICs na sua execução, permitindo que as atividades sejam exercidas extramuros empresariais, e marcada pela falta de controle da jornada de trabalho.

Em conformidade com a tendência mundial de flexibilizar as relações laborais e diante do cenário pandêmico vivenciado, o teletrabalho cresceu exponencialmente nos últimos anos, tornando-se uma realidade para grande parte dos trabalhadores. Com sua crescente utilização, fez-se necessário realizar inovações legislativas no ordenamento jurídico brasileiro a fim de acompanhar tais mudanças. Nesse cenário, a Reforma Trabalhista, inseriu na Consolidação das Leis Trabalhistas (CLT) um capítulo destinado a regulamentar o teletrabalho.

Malgrado a regulamentação, as preocupações concernentes a esse novo regime de trabalho ainda persistem, visto a crescente exposição dos teletrabalhadores a sobrejornada uma vez que, nos termos do art. 62, III da CLT, essa modalidade de trabalho está excluída do regime de controle de jornada.

Nesse contexto, os teletrabalhadores estão sujeitos a situações prejudiciais à sua saúde física e mental, sendo necessário garantir, portanto, o seu direito à desconexão, isto é, o direito de não trabalharem ininterruptamente e de poderem usufruírem de momentos de lazer.

Trata-se de estudo teórico-normativo, que utiliza o método dedutivo para responder ao seguinte problema de pesquisa: de que forma o uso do teletrabalho impacta na saúde física e mental do teletrabalhador?

O texto encontra-se dividido em cinco itens, sendo o primeiro esta introdução; o segundo aborda questões acerca do teletrabalho, suas características e como ele é regulamentado no ordenamento jurídico brasileiro; o terceiro apresenta os reflexos do teletrabalho na saúde física e mental dos teletrabalhadores; o quarto item evidência o direito à desconexão como um direito fundamental. Por fim, o quinto e último item apresenta as considerações finais deste estudo.

\section{O TELETRABALHO NO ORNDEMANETO JURÍDICO BRASILEIRO}


Nos anos 70, com as crises do petróleo e do modelo de produção fordista, surge a necessidade de reduzir os gastos das empresas, flexibilizar as formas rígidas de produção e controle de trabalho, bem como otimizar o tempo de deslocamento dos trabalhadores (HARVEY, 2014).

É nesse contexto que o teletrabalho ganhou destaque, uma vez que permitia essa redução de custos, não havia desperdício de tempo com deslocamento dos trabalhadores e diminuía significativamente os custos com o ambiente de trabalho (SILVA, FIGUEIRA, 2017)

Por isso, após seu surgimento, o teletrabalho ganhou força e expressividade no mundo contemporâneo do trabalho, em especial pelos avanços das tecnologias de informação e comunicação (TICs).

O teletrabalho é uma modalidade de trabalho realizado à distância, isto é, fora do espaço físico da empresa, mas não necessariamente um trabalho em domicílio, podendo ser realizado em qualquer lugar. Sua característica principal é a utilização de TICs, e a flexibilidade na realização desse tipo de trabalho, em contraste com a rigidez preponderante dos modelos fordistas. ${ }^{1}$

É importante mencionar que, no momento em que a Consolidação das Leis Trabalhistas (CLT) foi promulgada, o teletrabalho não foi regulamentado por não ser uma realidade do mercado de trabalho brasileiro à época. Os primeiros traços de normatização ocorreram apenas em 2011, com o advento da Lei 12.551, que modificou o artigo $6^{\circ}$ da CLT, que em sua nova redação estabeleceu não haver distinção "[...] entre o trabalho realizado no estabelecimento do empregador, o executado no domicílio do empregado e o realizado a distância, desde que estejam caracterizados os pressupostos da relação de emprego".

Contudo, a regulamentação realizada foi aquém da complexidade e dos pormenores desta modalidade de trabalho. Apenas com o advento da Lei 13.467 de 2017, conhecida como "Reforma Trabalhista", que houve o detalhamento da normatização do teletrabalho, no Capítulo II-A da CLT.

\footnotetext{
${ }^{1}$ De acordo com Harvey (2014), o modelo fordista é caracterizado pela produção em massa através de um processo mecanizado e padronizado com base em linhas de montagem. O trabalho na produção fordista é marcado pela rigidez, degradação e coisificação dos trabalhadores, os quais realizam atividades específicas e repetitivas, porém, em contrapartida, é um trabalho regularizado e sindicalizado.
} 
De acordo com o novo art. 75-B da CLT, o teletrabalho é compreendido como a "[...] prestação de serviços realizadas preponderantemente fora das dependências do empregador, com a utilização de tecnologias de informação e de comunicação, que por sua natureza, não se constituam como trabalho externo". Ademais, o mencionado dispositivo, em seu parágrafo único, destaca que o comparecimento do empregado às dependências da empresa, para a realização de atividade específica, não descaracteriza o teletrabalho.

A adoção deste regime de trabalho deve constar, nos termos do art. 75-C da CLT, expressamente no contrato individual de trabalho, o qual especificará as atividades que serão realizadas pelo empregado. A alteração do regime presencial ao regime de teletrabalho poderá ocorrer através de mútuo acordo entre as partes, no entanto o inverso poderá ocorrer por determinação do empregador, garantindo prazo mínimo de 15 dias para o empregado realizar a transição entre os regimes, não se olvidando que qualquer alteração deverá constar em termo aditivo contratual.

Do mesmo modo, também deve estar previsto em contrato escrito, a responsabilidade pela aquisição, manutenção ou fornecimento dos equipamentos tecnológicos, bem como pela adequação da infraestrutura necessária à prestação do trabalho remoto. De acordo com o art. 75-D, o direito ao reembolso das despesas arcadas pelo empregado, também deve estar pactuado em contrato escrito e não a sua remuneração.

Cabe acrescentar a crítica feita por Bezerra Leite (2021) ao art. 75-D. O autor destaca que esse dispositivo permite a transferência do risco da atividade econômica ao trabalhador, contrariando a principiologia protetiva trabalhista, uma vez que através de contrato escrito o empregador poderá determinar que os custos pela aquisição e manutenção do aparato tecnológico seja arcado pelo trabalhador, levando ao aumento da desigualdade, já imbricada no mercado de trabalho.

No que concerne a precaução a ser tomada para evitar doenças e acidentes de trabalho, o artigo 75-E preceitua que o empregador deverá instruir os empregados, de maneira expressa e ostensiva, sobre os cuidados que devem tomar durante o regime de teletrabalho. $O$ empregado deverá assinar termo de responsabilidade, comprometendo-se a seguir as instruções fornecidas pelo empregador.

No mais, o artigo 62, III, da CLT, preceitua que os teletrabalhadores não são abrangidos pelas normas concernentes ao controle de jornada e, por conseguinte, não fazem jus ao recebimento de horas extras. 
Esta modalidade de trabalho estava, gradativamente, ganhando cada vez mais espaço, contudo, em decorrência do cenário pandêmico vivenciado pelo mundo, a utilização do teletrabalho aumentou de maneira exponencial, a fim de evitar a proliferação do vírus SARSCoV-2. Inclusive, segundo pesquisa realizada pelo IBGE (2020), atualmente, 96\% dos participantes abordados estão trabalhando neste regime.

Desse modo, o aumento significativo da utilização dessa modalidade de trabalho ocasiona uma maior preocupação com a saúde dos teletrabalhadores, visto que o arcabouço legislativo existente prestigia a não limitação da jornada desse tipo de trabalhador, exigindo, muitas vezes, que ele esteja constantemente disponível aos chamados do empregador.

Uma vez explanados os artigos que regulamentam o uso do teletrabalho, adentra-se na questão central deste estudo para analisar os impactos que esse regime de trabalho pode ocasionar à saúde física e mental dos trabalhadores.

\section{OS REFLEXOS DO TELETRABALHO NA SAÚdE FÍSICA E MENTAL DO TRABALHADOR}

Para Bakuri (2018), o trabalho pode ser fonte de saúde e de adoecimento dos trabalhadores. Isso porque quando há o equilíbrio entre os fatores humanos e as condições laborais, a saúde é afetada positivamente. Entretanto, o oposto também é verdade, isto é, em um cenário de desequilibro entre esses dois fatores, ocorre o adoecimento do trabalhador.

O direito à saúde, física e mental, do trabalhador no meio ambiente laboral é um direito fundamental, pois é apenas com seu cumprimento que é possível falar em trabalho digno e decente.

A preocupação com o resguardo a saúde dos trabalhadores ganhou novos contornos com a introdução das tecnológicas de informação e comunicação (TICs) no meio ambiente do trabalho e com o surgimento de novas organizações trabalhistas moldadas pela lógica digital.

A mudança do fordismo à acumulação flexível, inquestionavelmente trouxe benesses aos trabalhadores, os quais puderam deixar de lado as rotinas enfadonhas, repetitivas e rígidas para uma rotina de trabalho mais flexível. Porém, por outro lado, junto com flexibilização do modo de execução dos serviços, veio a facilidade em flexibilizar e desmontar direitos trabalhistas a fim de enquadrá-los a ordem do capital. 
Como dito alhures, nesse contexto de flexibilização que surge o teletrabalho e, por conseguinte, a inexistência de jornada pré-definida e de espaço laboral físico ao desempenho de sua atividade.

Ferreira e Sabino (2020) observam que essa nova realidade trouxe benefícios à rotina dos trabalhadores, permitindo a maleabilidade de horários; a possibilidade de conciliação da vida profissional com a familiar; a melhora na qualidade de vida, visto que os trabalhadores não precisam se deslocar e enfrentar engarrafamentos; menos poluição, já que propicia a diminuição da circulação de carros na rua.

Contudo, como apontado por Antunes (2020), é utópico acreditar que o teletrabalho trouxe mais benesses do que malefícios aos trabalhadores. A perda da identidade coletiva, o isolamento social, a dupla jornada, o adoecimento e a gradativas eliminações de proteções trabalhistas virou uma triste realidade aos proletariados da era digital.

O adoecimento do trabalhador não iniciou na era digital, mas é inquestionável que ocorreu uma intensificação por esse fator e novas imediações surgem que precisam ser analisadas, a fim de evitar que esse cenário seja um vetor de doenças ocupacionais.

Em virtude da complexidade desse novo ambiente do trabalho, não basta analisar isoladamente os fatores de risco no ambiente, é necessário olhar para outras dimensões que refletem no custo humano, isto é, aquilo que deve ser despendido pelo obreiro nas esferas físicas, cognitivas e afetivas, bem como o prazer e o sofrimento no trabalho, suas consequências para a saúde física, psíquica e os danos sociais correlatos (JOSÉ FILHO, 2020).

Primeiramente, analisa-se a saúde física dos teletrabalhadores, uma vez que eles não detêm um espaço físico definido como ambiente de trabalho, desfrutando a permissibilidade de laborarem em qualquer espaço físico, desde que possuam acesso às TICs.

Essa permissibilidade e flexibilidade do teletrabalho, como dito, traz vantagens aos seus adeptos, mas não se pode olvidar os problemas relacionados à saúde físicas enfrentados por esses teletrabalhadores.

Em estudo publicado pela European Journal Of Environmentt and Public Health, contatou-se que é cediço na literatura ergométrica os malefícios que o telework causa a saúde física, devido à má postura, movimento repetitivo e longas horas contínuas de trabalho, sem intervalo, podem causar distúrbios osteomusculares, particularmente dores nos membros superiores e inferiores e dores na lombar (BUOMPRISCO; RICCI; PERRI; DE SIO,2021). 
O estudo demonstrou também que o teletrabalho está relacionado ao aumento do sedentarismo e inatividade física, que podem contribuir, a longo prazo, com o aparecimento de doenças crônicas, como diabetes, doenças cardiovasculares, obesidade e hipertensão (BUOMPRISCO; RICCI; PERRI; DE SIO,2021).

No mais, outras doenças ocupacionais relacionadas ao teletrabalho são as oculares. Averiguou-se que longas horas na frente do computador a longo prazo ocasiona alterações significativas nos resultados do tempo de ruptura da lágrima do tipo evaporativo de secura ocular, podendo levar a uma doença de olho seco do tipo evaporativo (AKKAYA, ATAKAN, ACIKALIN, AKSOY, OZKURT, 2018).

Em pesquisa publica pela Indian Journal of Ophthalmology, verificou-se que o crescente uso de dispositivo digital, em virtude do aumento do teletrabalho pelo cenário pandêmico, ampliou a deterioração da saúde ocular em todas as faixas etárias e a fadiga ocular (BAHKIR, GRANDEE, 2020)

As doenças tratadas acima são apenas alguns exemplos dos malefícios à saúde do teletrabalhador, de fato, fica clarividente o nexo causal entre seu labor e as enfermidades. A situação é agravada quando se depara com uma legislação trabalhista que, ao tratar sobre a precaução a acidentes no teletrabalho, afirma que a única responsabilidade do empregador é realizar instruções expressas e ostensivas sobre como o trabalho deve ser executado e, após orientação, o empregado deve assinar termo de responsabilidade.

Essa (des)regulamentação veio em um contexto de desmonte dos direitos sociais trabalhistas e de uma tendência a precarização da mão de obra, o que fica evidente quando se transfere ao trabalhador a obrigação de assinar termo de responsabilidade, pois, o escopo desse termo é a isenção de responsabilidade pelas empresas em relação a saúde e segurança desse trabalhador, levando a uma diminuição dos custos e responsabilidades trabalhistas.

Essa circunstância que pode ser ainda mais agravada caso as partes acordem que o empregado será o responsável pela aquisição do material necessário à realização do teletrabalho, pois é natural que esta escolha produtos mais acessíveis, a fim de minimizar seus custos, o que levará, provavelmente, a compra de produtos não ergométricos e que, a longo prazo, trará o adoecimento deste trabalhador.

Não se pode olvidar que esse cenário ainda é mais preocupante em virtude a intensa desigualdade social enfrentada pelo país, o que levará a população mais pobre a comprar produtos mais baratos de qualidade duvidosa e/ou sem certificações pela INMETRO, os quais 
não garantirão sua saúde. Em contraste, trabalhadores que possuem condição financeira mais favorável terão a oportunidade de investir nesses aparatos e tentar resguardar sua saúde.

Inicialmente, pontuou-se os problemas gerados à saúde física dos teletrabalhadores, sendo necessário agora analisar questões relacionadas ao adoecimento mental daqueles.

Acerca desse assunto é interessante notar que a preocupação com os riscos psicossociais no meio ambiente de trabalho remota os anos 80, mais especificamente 1984, quando a Organização Internacional do Trabalho (OIT) apontou à importância de identificar e combater os fatores de riscos psicossociais, que consistem, por um lado, "na interação entre o trabalho, seu ambiente, a satisfação no trabalho e as condições de sua organização", e, por outro, na capacidade do obreiro, nos seus anseios, nas suas relações particulares, na sua cultura e tudo aquilo que pode influenciar na vida e na saúde do trabalhador (CAMELO, ANGERAMI, 2008).

Assim, os riscos psicossociais abarcam fatores relacionados ao meio ambiente do trabalho, como por exemplo, organização, gestão e contexto social, que podem afetar negativamente a saúde mental do trabalhador, abalando seu estado emocional e psicológico.

Nesse sentido, o Instituto Nacional de Saúde Pública de Quebec (INSPQ) conceitua riscos psicossociais como "[f]atores que estão ligados à organização do trabalho, práticas de gestão, condições de emprego e relações sociais e que aumentam a probabilidade de causar efeitos adversos na saúde física e psicológica das pessoas expostas” (INSPQ, 2016).

Entre as categorias dos fatores de riscos psicossociais na vida do trabalhador, Camelo e Angerami (2008) apontam, exemplificativamente, as seguintes classes: relacionamento interpessoal no trabalho, interface trabalho-família, carga e ritmos de trabalho e esquema de trabalho.

Em síntese, essas categorias tratam de dois aspectos centrais: a sociabilidade do trabalhador e sua jornada de trabalho. Ambos se interligam, visto que as longas horas de trabalho afetam diretamente a sociabilidade do obreiro no seu ambiente familiar, fazendo com que surja um distanciamento afetivo entre o trabalhador e sua família, mesmo nos casos que os obreiros exercem sua função dentro de suas residências.

Em interessante classificação sobre as patologias mentais que acometem os trabalhadores, Dejours (2008) as dividiu em quatro categorias: a) as patologias de sobrecarga; b) as patologias pós-traumáticas; c) as patologias de assédio; e d) depressões, tentativas de suicídio e suicídios. 
Nesse artigo, optou-se por abordar as patologias de sobrecarga envolvendo o teletrabalhador. Como dito, o mito da flexibilidade e da permissibilidade de uma vida mais equilibrada não vingou. Pelo contrário, os teletrabalhadores demonstram que essas características dentro de uma relação laboral não são sinônimo de liberdade, mas podem estar próximas a uma "escravidão digital”, conforme apontado por Antunes (2020).

A sobrecarga, destaca Baruki (2018), é caracterizada pela grande quantidade de tarefas, pela pressão do tempo e pela falta de separação entre vida profissional e pessoal. Em especial ao teletrabalhador, essa sobrecarga e seus fatores de riscos estão relacionados a sua não desconexão, e a sua constante disponibilidade através das TICs.

Sobre o tema, evidência Standing (2017) que “[...]o mercado global é uma máquina que funciona no esquema de 24/7; nunca dorme ou relaxa; não tem nenhum respeito pela luz do dia ou escuridão; pela noite ou pelo dia.”, ou seja, não há qualquer preocupação com a saúde e o bem-estar do trabalhador, com os seus momentos de descanso, ócio ou lazer.

Isso pode ser visualizado na pesquisa realizada pelo IBGE, em julho de 2020, na qual um percentual expressivo de trabalhadores afirmou que realizaram teletrabalho em dias considerados de descanso. Dentre os entrevistados, 50\% realizaram alguma atividade de trabalho aos sábados e $37 \%$ aos domingos. No quesito trabalho no feriado, $61 \%$ das pessoas entrevistadas responderam que trabalharam em algum feriado (IBGE, 2020).

Essa sobrecarga de labor poderia ser evitada, caso a legislação brasileira não tivesse inserido o teletrabalho dentre as modalidades de trabalho que não possuem controle de jornada, no art. 62 da CLT.

Nesse contexto de sobrecarga, algumas patologias podem acometer os teletrabalhadores, como, por exemplo, a Síndrome de Burnout, irritabilidade, solidão e frustração.

A Síndrome de Burnout ou Síndrome do esgotamento profissional é caracterizada pelo quadro de exaustão extrema, física e mental, estresse somático, falta de energia, o qual leva o indivíduo a impossibilidade de realizar atividades rotineiras (OLIVEIRA, TOURINHO, 2020).

Reconhecida pelo Ministério da Saúde como transtorno mental e do comportamento relacionado ao trabalho, por meio da Portaria $n^{\circ} 1339 / 99$, bem como pelo Decreto $n^{\circ}$ 6.042/07, possui como fatores de risco "o excesso de trabalho, recompensa insuficiente, alto 
nível de exigência psicológica, baixo nível de liberdade de decisão e de apoio social e estresse" (BAKURI, 2018).

De acordo com Oliveira e Tourinho (2020), os trabalhadores que são diagnosticados com a Síndrome de Burnout apresentam quadro depressivo, falta de entusiasmo para realizar atividades laborais e pessoais, levando o trabalhador ao isolamento social.

Inclusive, o Tribunal Superior do Trabalho (TST) já possuí decisões condenando as empresas a pagar indenização por danos morais aos trabalhadores que desenvolveram a patologia devido às más condições de trabalho, como por exemplo o julgamento abaixo:

AGRAVO DE INSTRUMENTO EM RECURSO DE REVISTA INTERPOSTO NA VIGÊNCIA DA LEI No 13.015/2014. INDENIZAÇÃO POR DANOS MORAIS. FIXAÇÃO DO VALOR DA INDENIZAÇÃO. CONCAUSA. COBRANÇA EXACERBADA DE METAS INATINGÍVEIS. SÍNDROME DE BURNOUT. OFENSA AOS ARTIGOS $5^{\circ}$, INCISO V, DA CF/88 E 944 DO CC/2002. INOCORRÊNCIA. I - para bem equacionar a controvérsia em torno da fixação da indenização por dano moral, é importante ter em mente a sua distinção em relação à indenização por dano material, na medida em que esta se orienta pelo parâmetro meramente aritmético, consistente nos prejuízos sofridos e nos lucros cessantes, ao passo que aquela tem por norte o escorregadio parâmetro estimativo, dada a dificuldade de mensuração pecuniária de bens imateriais. II - Resulta dessa particularidade o insuspeitado subjetivismo do magistrado na sua fixação, subjetivismo que moveu a doutrina e a jurisprudência a procurar estabelecer critérios mínimos para que o seu arbitramento não se convole em arbitrariedade. III - Isso com a finalidade de que o seu valor não se revele demasiadamente apequenado, nem se afigure superlativamente alto, traduzindo antes justa reparação do dano sofrido pelo empregado, sem acarretar o seu enriquecimento sem causa, capaz de comprometer, até mesmo, a viabilidade do empreendimento empresarial. IV - Com isso se preconiza que se considere a gravidade da culpa lato sensu do ofensor, que o pode ser a título de dolo, culpa grave, leve ou levíssima, a extensão do dano causado, a sua capacidade econômico-financeira, bem como o caráter pedagógico da sanção jurídica. V - E bom ter em mente, ainda, o que dispõe o inciso IV do artigo $1^{\circ}$ do Texto Constitucional de a República Federativa do Brasil lastrear-se nos valores sociais do trabalho e no da livre iniciativa, norma indicativa de que o Constituinte originário os colocara no mesmo patamar de valores republicanos fundamentais. VI - Tal se deve ao objetivo ali discernível de expressar a harmonia que deve haver entre ambos, a desafiar de todos quantos lidam com o Direito do Trabalho a sensibilidade de se evitar que um se sobreponha ao outro, pois tais valores se encontram em situação de equipolência e não de antagonismo. VII - É de vital importância, portanto, que todos os profissionais do direito, ao se defrontarem com a magnitude dessa questão, atuem com extremada prudência, para prevenir que a exacerbação do valor da livre iniciativa transforme o trabalho humano em simples e abjeta mercadoria ou que a exacerbação dos valores sociais do trabalho redunde no comprometimento da empresa, fonte geradora de renda e de emprego. VIII - Demonstrada a ocorrência de culpa do agravante, por propiciar o desenvolvimento da 
Síndrome de Burnout em seu empregado, a extensão expressiva do dano causado, com reflexo psicológico negativo insuperável que se abatera sobre o agravado, somado à elevada capacidade econômico-financeira da empresa e, sobretudo, o caráter pedagógico da sanção jurídica, afigura-se proporcional e razoável manutenção da indenização por dano moral no importe $\mathrm{R} \$ 100.000,00$ (cem mil reais), não se divisando, dessa forma, violação literal e direta ao artigo 944 do Código Civil, a teor do artigo 896, alínea c, da CLT. IX - Registre-se a impertinência da indigitada afronta ao inciso $\mathrm{V}$ do artigo $5^{\circ}$ da Constituição, haja vista que ele limita-se a assegurar o direito à indenização pelo dano moral, sem dilucidar parâmetros para o seu arbitramento, ou a dispor sobre a restituição decorrente de enriquecimento sem causa. X - Agravo de instrumento a que se nega provimento. (TST AIRR: 22568120145120060, Relator: Antônio José de Barros Levenhagen, Data de Julgamento: 08/02/2017, $5^{\text {a }}$ Turma, Data de Publicação: DEJT $10 / 02 / 2017)$

De modo similar, o TST decidiu pela reintegração do trabalhador dispensado quando portador da patologia, a fim de preservar a garantia provisória de emprego ao trabalhador acidentado. Acompanhe:

RECURSO ORDINÁRIO EM MANDADO DE SEGURANÇA. TUTELA PROVISÓRIA DE URGÊNCIA DEFERIDA NA RECLAMAÇÃO TRABALHISTA. REINTEGRAÇÃO DE EMPREGADA DISPENSADA QUANDO PORTADORA DE SÍNDROME DE BURNOUT. NEXO DE CAUSALIDADE COM A PRESTAÇÃO DE SERVIÇOS PARA O EMPREGADOR. AUSÊNCIA DE ILEGALIDADE. 1. Mandado de segurança impetrado contra decisão interlocutória de deferimento de tutela provisória de urgência, na qual determinada a reintegração de empregada portadora de Síndrome de Burnout, com restabelecimento do plano de saúde corporativo e emissão de CAT. 2. O mandado de segurança é a ação prevista no artigo $5^{\circ}$, LXIX, da Constituição Federal, disciplinado na Lei $12.016 / 2009$, visando a proteger direito líquido e certo, não amparado por habeas corpus ou habeas data, quando o responsável pela ilegalidade ou abuso de poder for autoridade pública ou agente de pessoa jurídica no exercício de atribuições do Poder Público. A concessão do writ está condicionada à demonstração de ato ilegal ou abusivo da autoridade coatora e do direito líquido e certo da Impetrante. 3. In casu, a autoridade apontada como coatora pontuou que a Litisconsorte passiva é portadora de Síndrome de Burnout, com tratamento em curso, que estava com a capacidade laborativa comprometida ao tempo da dispensa e que havia nexo de causalidade entre o adoecimento e a prestação de serviços. 4. A decisão preserva, em princípio, a garantia provisória de emprego ao trabalhador acidentado, na forma do artigo 118 da Lei $\mathrm{n}^{\circ} 8.213 / 1991$, em sintonia com a diretriz da Súmula 378, II, e da OJ 142 da SBDI-2 do TST, na medida em que reconhecida a doença ocupacional após a dispensa, bem como o nexo de causalidade com a prestação de serviços, ainda que ausente o afastamento superior a quinze dias. 5. Não há violação do artigo $6^{\circ}, \S 2^{\circ}$, da Lei $605 / 1949$, preceito legal que não estabelece hierarquia entre os profissionais médicos que possam atestar a incapacidade laborativa do trabalhador ou a caracterização de doença ocupacional, mas apenas a prevalência dos atestados da instituição da Previdência Social, do médico do Serviço Social 
do Comércio ou Indústria e do médico da empresa ou por ela designado para efeito de justificação de ausência com preservação da remuneração. 6. A eventual descaracterização da enfermidade que acomete a Litisconsorte passiva como doença ocupacional é providência que reclama o exame aprofundado da controvérsia, com dilação probatória, insuscetível de viabilização no mandado de segurança. Desse modo, por ora, demonstrada a probabilidade de que o direito invocado na reclamação trabalhista realmente exista, ao lado do periculum in mora, não há espaço para concessão da segurança e cassação da tutela de urgência deferida no feito originário. 6 . Segurança denegada. Recurso ordinário conhecido e não provido. (TST RO: 69335420175150000, Relator: Douglas Alencar Rodrigues, Data de Julgamento: 18/09/2018, Subseção II Especializada em Dissídios Individuais, Data de Publicação: DEJT 28/09/2018)

O trabalho remoto apresenta alguns desses fatores de risco psicossocial capazes de desenvolver a Síndrome de Burnout, visto que a maioria desses trabalhadores não possuem uma jornada de trabalho definida e tendem a permanecer trabalhando após o horário de expediente. Além disso, o isolamento social também se apresenta como um fator de risco, na medida que são privados de interações sociais que não apenas auxiliam na realização do trabalho, como também promovem uma vida mental mais saudável.

A solidão dos teletrabalhadores é um dos fatores de maior risco ao desenvolvimento de patologias mentais. Em estudo realizado por Mann e Holdsworth (2003), constatou-se que uma das maiores queixas dos trabalhadores remotos é a falta de interação, ausência de comunicação e a falta de apoio social.

Nas entrevistas realizadas com 12 jornalistas em tempo integral da Trinity Mirror plc e da Times Newspapers Ltda, alguns trabalhadores relataram que sentem a necessidade de sair de casa e ir às lojas para conseguir interagir com as pessoas e ter contato humano, caso contrário não conseguem aguentar as pressões do trabalho (MANN; HOLDSWORTH, 2003).

Assim, conforme apontado por Delgado, Assis e Rocha (2020), a solidão provoca uma frustação nos trabalhados que não conseguem vislumbrar os resultados efetivos e a importância do seu trabalho, não sendo mais reconhecido no trabalho e pelo trabalho, malgrado as longas jornas.

Nesse contexto, sentimentos como frustação e irritabilidade viram rotineiros aos trabalhadores. Conforme apontado por Mann e Holdsworth (2003), esses sentimentos negativos de fato são mais presentes no regime de teletrabalho, visto a distância física da fonte de quaisquer problemas, gerando uma limitação na capacidade de resolver problemas, levando esses trabalhadores a sentimentos de frustação e irritabilidade. 
No mais, Mann e Holdsworth (2003) constataram que outra fonte de frustação é a constante interrupção dos membros da família na rotina dos teletrabalhadores. O fim da fronteira entre trabalho e vida doméstica, conduz os membros da família desse trabalhador a possuírem dificuldades em distinguir os horários destinados ao trabalho e os destinados ao seio familiar.

Nesse cenário de sobrejornada e isolamento social, surge o questionamento sobre o direito dos trabalhadores de se desconectarem de seu labor, de usufruírem de seu direito ao lazer, sem constrangimento e sem julgamento, a fim de resguardar sua saúde física e mental.

\section{O DIREITO À DESCONEXÃO COMO UM DIREITO FUNDAMENTAL}

Com o surgimento da era tecnológica muito se questionou sobre a substituição do trabalho humano pelas novas tecnologias, a preocupação com o fim das relações laborais subsistiu no inconsciente coletivo, entretanto o que se percebe, na verdade, é uma intensificação do trabalho em virtude das novas tecnologias, o que Antunes (2020) chama de "escravidão digital".

O avanço tecnológico e o surgimento de tecnologias de informação e comunicação permitiram que o controle, comunicação e os processos entre trabalhador e empresa se aproximassem, se intensificassem e se perpetuassem. $O$ trabalho agora pode ser realizado a qualquer momento e em qualquer lugar. O trabalhador precisa estar disponível constantemente, independente do horário de expediente.

Malgrado os benefícios que as TICs trazem aos trabalhadores e ao meio ambiente laboral, elas acabam por permitir que violações reiteradas aos direitos sociais trabalhistas ocorram, visto que elas flexibilizam e facilitam o acesso ao trabalhador 24 horas por dia, através de mensagens em aplicativos de comunicação.

As TICs não são, por si sós, as criadoras de tais violações, são instrumentos facilitadores da perpetuação de abusos por partes dos empregadores, que acreditam que seus teletrabalhadores precisam estar disponíveis aos seus anseios e ordens a todo momento, independente do horário.

Os teletrabalhadores ficam privados de qualquer momento de lazer, a despeito de trabalharem dentro de suas próprias residências, acabando por gerar quadros de patologias físicas e mentais, como já abordado. Tal adoecimento também é maléfico as empresas, que 
necessitam de mão de obra saudável e descansada para executar suas atividades de maneira eficiente.

Por conta do adoecimento dos trabalhadores, em decorrência de longas horas de trabalho e de sua constante disponibilidade através de TICs, é imperioso trazer à baila a necessidade de resguardar o direito à desconexão dos trabalhadores, a fim de garantir um trabalho digno e decente.

O direito à desconexão do trabalhador é o direito de se desconectar do labor, de descansar e de usufruir seu momento de lazer com energia e disposição, não deve se limitar a diversões moderadas em virtude da exaustão ou, pior, pela necessidade de estar sempre à disposição. Tal direito deve ser garantido aos que trabalham na modalidade telepresencial-

Nesse sentido, Ferreira, Rocha e Ferreira (2020, p. 441) preceituam que:

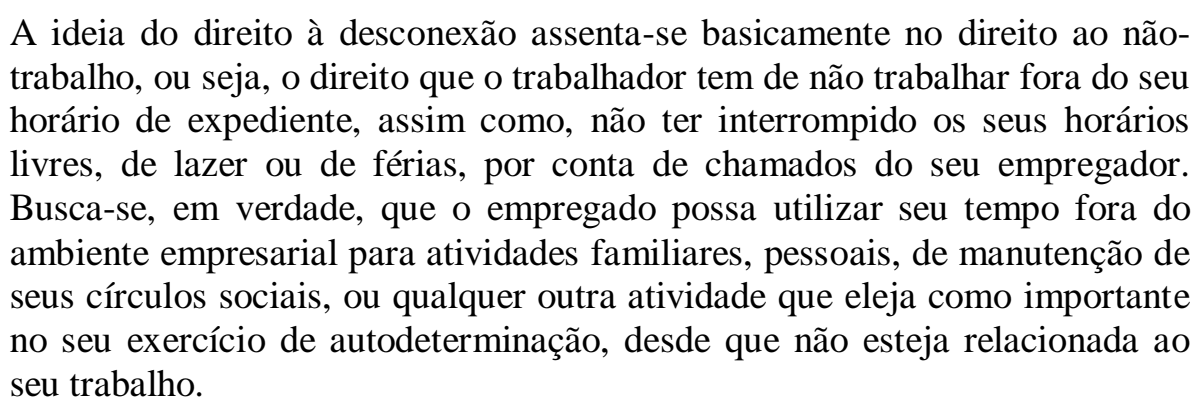

Desse modo, a tecnologia não pode escravizar seus usuários, submetendo-os a jornadas de trabalho extensas e mesclando seu ambiente laboral com seu ambiente de prazer, através da abertura desse canal de comunicação, direto e ininterrupto, entre empregadoempregado, pois, se assim o for, ocasionará sérios riscos psicossociais aos trabalhadores (FERREIRA, ROCHA, 2020).

Nesse sentido, Souto Maior (2003) afirma que quando se trata do direito à desconexão, ou o direito de não trabalhar, não está tratando de uma questão meramente filosófica ou relacionada ao futuro, também não se está falando do direito de ser leigo, mas sim de uma perspectiva técnica-jurídica, com a finalidade de identificar um bem da vida, o não trabalho, cuja preservação possa se dar em concreto, através da persecução em juízo.

Para Souto Maior (2003) ainda é necessário esclarecer que o direito à desconexão não significa o direito ao não trabalho por completo, mas sim no sentido de trabalhar menos, dentro de um determinado horário que permita que esse trabalhador consiga preservar sua saúde, física e mental, e consiga usufruir de momentos de lazer. 
Com a garantia ao direito à desconexão, o teletrabalhador terá o direito de não ficar à disposição do trabalho ininterruptamente, tendo o direito, inclusive, de ficar on-line para fins recreativos, direito ao ócio e ao descanso, desligando-se totalmente do trabalho.

O direito à desconexão é uma especialidade do direito ao descanso, isso porque a ideia central está vinculada com a era digital e as tecnologias de informação e comunicação. Por esse motivo que o Direito Francês regulamentou, através da Lei n 2016-1088, o direito à desconexão, malgrado o ordenamento jurídico já resguardasse sobre o tempo efetivo de trabalho (PONZILACQUA; SILVA, 2020).

Embora passível de críticas, a legislação francesa constitui um avanço à efetivação das limitações de jornada aos trabalhadores que utilização meios tecnológicos na realização de suas tarefas.

Para Freitas (2021), embora o ordenamento jurídico brasileiro não possua um dispositivo normativo expresso sobre o direito à desconexão, este direito é resguardado aos trabalhados através de uma interpretação integrativa das normas e princípios constitucionais e trabalhistas. Exemplos disso é a limitação de jornada de trabalho em oito horas diárias, direito aos intervalos intra e interjornada e direito ao descanso semanal remunerado.

Ademais, o direito à desconexão é necessário para resguardar a saúde dos teletrabalhadores, logo, o maior fundamento constitucional ao direito ao não trabalho é o direito à saúde e ao lazer, os quais são direitos sociais elencados no artigo $6^{\circ}$ da Constituição Federal, direito fundamentais para garantir uma vida digna e um trabalho decente aos trabalhadores (FREITAS, 2020).

Desta feita, o direito à desconexão do trabalho é um direito fundamental do trabalhador, pois é através de sua efetivação que o obreiro terá seus direitos indivíduas e sociais resguardados, visto que está relacionado ao direito à saúde, lazer, privacidade e intimidade (DORNELLES, MARDERS, 2020).

O teletrabalho é muito sensível as violações do direito à desconexão, visto que seu trabalho é refém do aparato tecnológico, mantendo-o conectado constantemente e ininterruptamente. A própria vida privada desses trabalhadores se confunde com sua vida profissional, ambas estão tão interligadas que é difícil saber onde uma começa e outra termina. O teletrabalhador é privado de momentos de lazer genuínos, momentos sem a tensão constantemente das mensagens em aplicativos de comunicação, fazendo com que a sua própria existência fique vinculada ao trabalho. 
Desse modo, são necessários mecanismos para coibir essas violações reiteradas aos teletrabalhadores, violações que causam danos irreparáveis a sua saúde física e mental, levando-os ao isolamento social, irritabilidade, depressão, exaustão e podendo ocasionar diversos problemas de saúde.

\section{CONSIDERAÇÕES FINAIS}

A inserção das tecnologias de informação e comunicação (TICs) no meio ambiente laboral se tornou um dos pontos centrais dos novos rumos do mercado de trabalho, criando-se a partir disso novos regimes, em especial o teletrabalho.

Essa nova modalidade de prestação de serviços traz à tona questões conflituosas, justapondo a promessa de um futuro do trabalho mais flexível e benéfico aos trabalhadores com previsões preocupantes sobre os impactos dos TICs à saúde física e mental desses teletrabalhadores.

São inquestionáveis as benesses que o teletrabalho pode proporcionar à vida dos trabalhadores, possibilitando que o trabalhador faça suas atividades em qualquer lugar, evitando o deslocamento até a empresa e permitindo que usufruam de mais tempo familiar. Contudo, malgrado os benefícios que essa modalidade de trabalho acarreta, é necessário observar se as normas de saúde e segurança do trabalho não estão sendo vilipendiadas.

Isso porque, como abordado no presente artigo, diversas doenças ocupacionais, ergométricas e mentais, estão relacionadas ao teletrabalho, em virtude da sobrejornada e do isolamento social tão marcantes nessa modalidade de trabalho.

Problemas relacionados à má postura, movimento repetitivo e longas horas de trabalho na frente celulares e computadores, como distúrbios osteomusculares e doenças oculares, estão na lista de enfermidades a que os teletrabalhadores estão suscetíveis. Além disso, o teletrabalho é marcado pelo aumento de sedentarismo e inatividade física, disfunções que a longo prazo podem levar a doenças crônicas, diabetes e doenças cardiovasculares.

Como já mencionado no decorrer deste estudo, o adoecimento não se limita as questões físicas. A carga e o ritmo do teletrabalho, bem como a falta de sociabilidade e a quebra da separação entre trabalho e família, desvia esses trabalhadores ao adoecimento mental. A Síndrome de Burnout, a irritabilidade, a solidão e a frustração são algumas das doenças que podem acometê-los. 
Assim, diante da utilização cada vez maior do teletrabalho, faz-se necessário criar mecanismos que impeçam o adoecimento do teletrabalhador e que sejam destinados a resguardar o seu direito fundamental à saúde.

Dessa forma, embora exista regulamentação legislativa para o uso do teletrabalho, é preciso que o direito à desconexão dos teletrabalhadores seja preservado, uma vez que a efetivação deste direito permite que o trabalhador usufrua de outros direitos fundamentais, tais como o próprio direito ao lazer, consagrado na Constituição Federativa do Brasil como um direito social.

Ademais, o respeito ao horário de trabalho - entenda-se: a uma jornada razoável previamente definida - assegura ao teletrabalhador o respeito à sua dignidade, uma vez que lhe permite o convívio familiar e social, tão necessário à preservação de sua saúde física e mental.

\section{REFERÊNCIAS}

AKKAYA, Sezean; ATAKAN, Tugba; ACIKALIN, Banu; AKSOY, Sibel; OZKURT, Yelda. Effects of long-term computer use on eye dryness. In: North Clin Istanb. 2018 Aug 8;5(4):319-322. Disponível em: https://www.ncbi.nlm.nih.gov/pmc/articles/PMC6371992/. Acesso em: 12 mar. 2021.

ANTUNES, Ricardo. Coronavírus (COVID-19): Epidemias - aspectos sociais. $1^{\text {a }}$ ed. São Paulo: Boitempo, 2020.

ANTUNES, Ricardo. O privilegio da servidão: o novo precariado de serviços na era digital. $2^{a}$ ed. São Paulo: Boitempo, 2020.

BAHKIR, Fayiqa Ahamed; GRANDEE Srinivasan Subramanian. Impact of the COVID-19 lockdown on digital device-related ocular health. In: Indian J Ophthalmol. 2020/Nov; 68. Disponível em: https://pubmed.ncbi.nlm.nih.gov/33120622/. Acesso em: 12 mar. 2021.

BARUKI, Luciana Veloso. Riscos Psicossociais e saúde mental do trabalhador: por um regime jurídico preventivo. $2^{\mathrm{a} e d . ~ S a ̃ o ~ P a u l o: ~ L T r, ~} 2018$.

BEZERRA LEITE, Carlos Henrique. Curso de direito do trabalho - $13^{\circ}$ ed. - São Paulo: Saraiva Educação, 2021.

BRASIL. Consolidação das Leis Trabalhistas (CLT), de 13 de julho de 2017. Disponível em: http://www.planalto.gov.br/ccivil_03/_ato2015-2018/2017/lei/113467.htm. Acesso em: 12 mar. 2021. 
BRASIL. Constituição Federal. Brasília: Senado Federal, 1988. Disponível em: http://www.planalto.gov.br/ccivil_03/constituicao/constituicao.htm. Acesso em: 12 mar. 2021.

BRASIL. Decreto n ${ }^{\circ}$ 6.042, de 12 de fevereiro de 2007. Altera o regulamento da previdência social, aprovada pelo Decreto $\mathrm{n}^{\circ} 3.048$, de 6 de maio de 1999, disciplina a aplicação, acompanhamento e avaliação do Fator Acidentário de prevenção - FAP e ao nexo técnico epidemiológico, e dá outras providencias. Disponível em:

http://www.planalto.gov.br/ccivil_03/_ato2007-2010/2007/decreto/d6042.htm. Acesso em: 12 mar. 2021.

BRASIL. Portaria ${ }^{\circ}$ 1339, de 18 de novembro de 1999. Disponível em: http://bvsms.saude.gov.br/bvs/saudelegis/gm/1999/prt1339_18_11_1999.html. Acesso em: 12 mar. 2021.

BUOMPRISCO, Giuseppe; RICCI, Serafino; PERRI, Roberto; DE SIO, Simone. Health and telework: new challenges after COVID-19 pandemic. In: European Journal of

Environmente and Public Health, v. 5, 2021. Disponível em:

https://www.ejeph.com/article/health-and-telework-new-challenges-after-covid-19-pandemic9705. Acesso em: 12 de mar. 2021.

CAMELO, Silva Helena Henriques.; ANGERAMI, Emília Luigia Saporiti. Riscos psicossociais no trabalho que podem levar ao estresse: uma análise da literatura. In: Ciência, Cuidado e Saúde, v. 7, n. 2, p. 234-240, 11 set. 2008. Disponível em: http://periodicos.uem.br/ojs/index.php/CiencCuidSaude/article/view/5010. Acesso em: 12 mar. 2021.

DEJOURS, Christophe. Alienação e clínica do trabalho. In: LANCMAN, S.; SZNELWAR, L. I. Christophe Dejours: da psicopatologia à psicodinâmica do trabalho. Rio de Janeiro: Editora Fiocruz; Brasília: Paralelo 15, 2008.

DELGADO, Gabriela Neves; ASSIS, Carolina Di; ROCHA, Ana Luísa Gonçalves. A melancolia no teletrabalho em tempos de coronavírus. In: Revista do Tribunal Regional do Trabalho da $3^{\circ}$ Região. Belo Horizonte, edição especial, t. I, p. 171-191, jul. 2020.Acesso em http://as1.trt3.jus.br/bd-trt3/handle/11103/55886. Acesso em: 12 mar. 2021.

DELGADO, Mauricio Godinho. Curso de direito do trabalho: obra revista e atualização conforme a lei da reforma trabalhista e inovações normativas e jurisprudenciais posteriores. $18^{\circ}$ ed.- São Paulo: LTr, 2019.

DORNELLES, Letícia; MARDERS, Fernanda. O direito à desconexão do trabalho: um direito humano fundamental. In: Revista eletrônica [do] Tribunal Regional do Trabalho da 9a Região, Curitiba, PR, v. 9, n. 89, p. 16-27, jun. 2020. Disponível em: https://juslaboris.tst.jus.br/handle/20.500.12178/179990. Acesso em: 12 mar. 2021.

FERRAZ DE OLIVEIRA, Luís Paulo; DE OLIVEIRA SOUZA TOURINHO, Luciano. Síndrome de Burnout, teletrabalho e revolução tecnológica: um estudo do adoecimento profissional em tempos de Covid-19. In: Revista Jurídica Trabalho e Desenvolvimento 
Humano, v. 3, 17 dez. 2020. Disponível em: http://www.revistatdh.org/index.php/RevistaTDH/article/view/83. Acesso em: 12 mar. 2021.

FERREIRA, Vanessa Rocha; ROCHA, Claudio da Rocha; FERREIRA, Versalhes. $O$ direito à desconexão e o dano existencial: a importância da sustentabilidade emocional do ser humano. In: Revista Direitos Sociais e políticas públicas, v. 8, n.2, mai.- ago./2020, p. 439471. Disponível em: http://www.unifafibe.com.br/revista/index.php/direitos-sociais-politicaspub/article/view/738/pdf. Acesso em: 12 mar. 2021.

FERREIRA, Vanessa Rocha; SABINO, Fabiana. As consequências do teletrabalho na saúde mental dos trabalhadores em tempos de COVID-19. In: Direito do trabalho e meio ambiente do trabalho I [Recurso eletrônico on-line] organização CONPEDI. (Coord.) Eloy Pereira Lemos Junior; Yuri Nathan da Costa Lannes. Florianópolis: CONPEDI, 2020, p. 89104. Disponível em:

http://conpedi.danilolr.info/publicacoes/n16180k3/37qj2s30/iPic5204GvJ8c5bQ.pdf. Acesso em: 19 mar. 2021.

FREITAS, Juliana Santos. Os impactos da tecnologia da informação e comunicação no direito à desconexão do trabalho. In: Brazilian Journal of Fevelopmente, v. 7, n 1, 2021. Disponível em:

https://www.brazilianjournals.com/index.php/BRJD/article/view/22601/18095. Acesso em: 12 mar. 2021.

IBGE. Instituto Brasileiro de Geografia e Estatística. Teletrabalho em tempos de pandemia - avaliação dos impactos para os trabalhadores. 2020. Disponível em:

https://assibge.org.br/confira-a-pesquisa-sobre-teletrabalho-no-ibge/. Acesso em: 12 mar. 2021.

\section{INSPQ. INSTITUTO NACIONAL DE SAÚDE PÚBLICA DE QUEBEC. Risques}

Psychosociaux du travail. 2016. Disponível em: https://www.inspq.qc.ca/risquespsychosociauxdu-travail-et-promotion-de-la-sante-des-travailleurs/risques-psychosociaux-dutravail. Acesso em: 12 mar. 2021.

JOSÉ FILHO, Wagson. Laborosfera: apontamentos para uma (res)significação do meio ambiente do trabalho digno e sustentável. In: Revista do Tribunal Superior do Trabalho: ano 86, n², abr./jun. 2020, p. 223-241. Disponível em:

https://juslaboris.tst.jus.br/handle/20.500.12178/176136. Acesso em: 12 mar. 2021.

HARVEY, David. Condição Pós-Moderna: uma pesquisa sobre as origens da mudança cultural. $17^{\circ}$ ed. Edição Loyola: São Paulo, 2008.

MANN, Sandi; HOLSWORTH, Lynn. The Psychological Impact of teleworking: stress, emotions and health. In: New Technology work and employment, v. 18, p. 196-211, nov. 2003. Disponível em: https://onlinelibrary.wiley.com/doi/abs/10.1111/1468-005X.00121. Acesso em: 12 mar. 2021.

PEREIRA PONZILACQUA, Marcio Henrique; SILVA, Luana Graciana. O direito à desconexão do trabalho francês: perspectivas de implementação no direito brasileiro. 
In: Revista Direito e Práxis, [S.1.], dez. 2020. ISSN 2179-8966. Disponível em: https://www.e-publicacoes.uerj.br/index.php/revistaceaju/article/view/53832. Acesso em: 12 mar. 2021.

SILVA, Leonardo Rabelo de Matos; FIGUEIRA, Hector Luiz Martins. As metamorfoses das relações laborais: o teletrabalho no tsunami neoliberal brasileiro. Revista do Tribunal Regional do Trabalho da 3. Região. Belo Horizonte, v. 63, n. 96, p. 183-203, jul./dez. 2017. Disponível em: http://as1.trt3.jus.br/bd-trt3/handle/11103/39026. Acesso em: 12 de mar. 2021.

SOUTO MAIOR, Jorge Luiz. Do direito à desconexão do trabalho. Revista do Tribunal Regional do Trabalho da $15^{\text {a }}$ Região, Campinas, SP, n. 23, p. 296-313, 2003. Disponível em: https://juslaboris.tst.jus.br/handle/20.500.12178/108056. Acesso em:12 mar. 2021.

STANDING, Guy. O precariado: a nova classe perigosa. $1^{\circ}$ edição. Belo Horizonte: Autêntica editora, 2017.

TST. Tribunal Superior do Trabalho. Agravo de Instrumento em Recurso de Revista $\mathbf{n}^{\circ}$ 2256-81.2014.5.12.0060. Relator Ministro Antonio Jose de Barros Levenhagen. Data de julgamento: 08/02/2017, $5^{\circ}$ turma, Data de publicação: DEJT 10/02/2017. Disponível em: https://tst.jusbrasil.com.br/jurisprudencia/429114726/agravo-de-instrumento-em-recurso-derevista-airr-22568120145120060/inteiro-teor-429114758. Acesso em: 12 mar. 2021.

TST. Tribunal Superior do Trabalho. Recurso Ordinário n6933-54.2017.5.15.0000. Relator Ministro Douglas Alencar Rodrigues. Data de julgamento 18/09/2018. Subseção II Especializada em Dissídios Individuais, Data de publicação: DEJT 28/09/2018. Acesso em: https://tst.jusbrasil.com.br/jurisprudencia/631857517/recurso-ordinario-trabalhista-ro69335420175150000/inteiro-teor-631857534. Acesso em: 12 de mar. 2021. 